\title{
Procesos urbanos. presentación número 6
}

\author{
Urban Processes. Presentation of number 6 \\ Processos Urbanos. Apresentação do número 6
}

\author{
Pedro Arturo Martínez Osorio. Ph.D(c). Design \\ pedro.martinez@cecar.edu.co \\ (iD) https://orcid.org/0000-0002-9024-0918 \\ Corporación Universitaria del Caribe - CECAR. Colombia \\ Alexandra Isabel Castellanos Tuirán. Arquitecta, M.Sc. Desarrollo y ambiente. \\ alexandra.castellanos@cecar.edu.co \\ (iD) https://orcid.org/0000-0003-3423-8714 \\ Corporación Universitaria del Caribe, CECAR, Sincelejo.
}

Con mucho gusto presentamos el número 6 de la revista científica Procesos Urbanos, adscrita a la Facultad de Ciencias Básicas, Ingeniería y Arquitectura de la Corporación Universitaria del Caribe - CECAR, Colombia.

En este número hemos reunido un grupo de artículos de gran actualidad y pertinencia para el desarrollo de las disciplinas de la arquitectura, el urbanismo y el diseño. Los cuales muestran los avances de importantes investigaciones y se reflexiona con relación a aspectos clave en el debate sobre las formas de habitar en el siglo XXI.

El primer artículo del presente número, de la arquitecta Ph.D. Beatriz García Moreno, es denominado "La ciudad de los habitantes y sus deseos", producto de la investigación "Ciudad, instituciones y deseos", de carácter teórico-crítico. Reflexiona sobre formas de apropiación y transformación de los espacios de la ciudad, en los cuales son de vital importancia no sólo las instituciones y organismos que dirigen la ciudad, sino también las prácticas de sus habitantes. La autora considera éstos, como seres hablantes provistos de deseo y de goce.

El segundo artículo denominado "Memoria, acontecimiento, objeto y lugar" de los arquitectos M.Sc. Juan Carlos Pérgolis Valsecchi y Estefanía Quijano Gómez, presenta los resultados de una investigación en la que se revisan las dualidades espacio / lugar, historia / memoria y relato oficial / múltiples relatos, a partir de las hipótesis: 1. Los acontecimientos convierten los espacios en lugares, por lo tanto, en "lugares de memoria"; 2. La historia propone un relato oficial único; la memoria se nutre de múltiples relatos. En el artículo se observan esas hipótesis en tres lugares: el histórico Puente de Boyacá, el Puente del Común y el puente urbano de la calle 116 con Avenida Boyacá, en Bogotá. Se cierra con una reflexión sobre el tema de la presencia del objeto de la memoria, tomando como ejemplo la intervención en el muelle de Puerto Colombia, Atlántico.

El tercer artículo "¿Cómo se habita el hábitat? Los modos de habitar" del arquitecto Esp. Alberto Saldarriaga Roa, hace parte de la investigación titulada "Hábitat y arquitectura en Colombia. Los modos de habitar". Se trabajan cuatro conceptos básicos: hábitat, habitar, cultura y arquitectura, y se estudia el papel que éstos desempeñan en la construcción de los modos de habitar.

A continuación, se presenta el artículo del economista, Ph.D. (c) en urbanismo Ronald Alejandro Macuacé Otero, denominado "Los espacios rururbanos en Colombia: algunos elementos para su discusión". Que reflexiona sobre los procesos rururbanos en Colombia, y genera una discusión interesante con relación a la producción del territorio en América Latina. El autor destaca que los procesos rururbanos son una realidad en las ciudades colombianas, independientemente de su tamaño, por lo cual sugiere un abordaje específico para ese fenómeno. 
El artículo "Capitolio Nacional de Colombia: aspectos biográficos del "Enfermo de Piedra" entre 1912 y 1914" del historiador M.Sc. José Alexander Pinzón Rivera, responde a la pregunta ¿cuáles fueron los cambios arquitectónicos y estilísticos, que se presentaron para la terminación del Palacio de Gobierno, de los poderes ejecutivo y legislativo de la Nación, entre 1912 y 1914 ?

A continuación, se presenta el artículo denominado "Los aljibes de Sincelejo. Una mirada desde la sostenibilidad", de los arquitectos Ph.D. (c) Gilberto Martínez Osorio, Judith Vergara Iglesia, Marianela Mendivil, y Francisco Monterroza Cuello, en el cual se presentan los resultados de una investigación que trabaja sobre la correspondencia entre los antiguos dispositivos de manejo del agua de la ciudad de Sincelejo, Colombia, con algunos sistemas actuales para el manejo sostenible del agua.

El siguiente artículo, del arquitecto Ph.D. Alejandro Guerrero Torrenegra, denominado "UPZ 67 Lucero Ciudad Bolívar, desde la perspectiva del imaginario y el mejoramiento integral". Tiene como objetivo principal, interpretar los imaginarios colectivos en las periferias espontáneas; toma como caso de estudio el Programa de Mejoramiento Integral de Barrios (PMIB), entre los años 2013-2015, en la UPZ 67 Lucero, de la localidad de Ciudad Bolívar en Bogotá.

A continuación, se presenta el artículo "Materiales locales y su influencia en la morfología de la Arquitectura" de los arquitectos Ph.D. Wendy Margarita Montes Ponce y Ph.D (c) Otniel Josafat López Altamirano. Los autores reflexionan sobre los aspectos tecnológicos y tectónicos en las búsquedas estilísticas de los arquitectos mexicanos a mediados del siglo XX.

El artículo "Proceso de diseño de una cubierta con el principio de tensegridad para espacios de esparcimiento" de los arquitectos José Abraham Mercado Escandón y Ph.D. Carlos Cesar Morales Guzmán. Los autores presentan los avances de una investigación sobre diseño de sistemas estructurales; muestran el procedimiento de diseño de una cubierta, soportada por el sistema estructural de tensegridad, e identifican la forma en que trabajan estas estructuras. También, analizan y desarrollan el procedimiento de patronaje para su construcción.

Se presenta a continuación el artículo de la economista M.Sc. en hábitat Gloria Zuleta Roa "La sustentabilidad en la edificación: desde el desarrollo -como categoría socioeconómica-, a la construcción sostenible". Este artículo de reflexión presenta la evolución histórica del concepto de sostenibilidad, con relación a la construcción del hábitat humano.

En ese mismo sentido, el siguiente artículo de la arquitecta Daniela Itsabe Castillejos Moguel, denominado "La ciudad sustentable: una aproximación a su conceptualización", se centra en conceptualizar la ciudad sustentable, desde sus orígenes y su transformación en el tiempo.

Para cerrar este número, un artículo del arquitecto Sebastián Arias Duque, denominado "El rio fantasma". El autor realiza una revisión de la evolución histórica del río Consotá, uno de los afluentes hídricos más importantes para la ciudad de Pereira y la región risaraldense en Colombia. Analiza también un proyecto para la recuperación de la cuenca del rio Consotá, con una visión de ciudad inclusiva.

Esperamos que estos artículos, las reflexiones y discusiones que plantean, sean de gran utilidad para el desarrollo de la investigación en torno a la construcción de la ciudad, el campo y el territorio con un enfoque sostenible. 